\title{
TENTATIVAS DEL CINE-GUERRILLA EN ARGENTINA EN LAS DÉCADA DEL SESENTA Y SETENTA
}

\author{
TENTATIVAS DO CINEMA-GUERRILHA NA ARGENTINA \\ NAS DÉCADAS DE SESSENTA E SETENTA
}

\author{
ATTEMPTS OF GUERRILLA-CINEMA IN ARGENTINA \\ IN THE SIXTIES AND SEVENTIES
}

\begin{abstract}
SILVANA FLORES
Licenciada en Artes. Doctoranda y becaria de la Universidad de Buenos Aires en el área de cine latinoamericano. Miembro del Centro de Investigación y Nuevos Estudios sobre cine (ClyNE), perteneciente al Instituto de Historia del Arte Argentino y Latinoamericano (UBA)
\end{abstract}

\section{RESUMEN}

Destacaremos la manera en que, desde la cinematografía argentina de los años sesenta y setenta, se produjo una extensión de las movilizaciones políticas, obreras y estudiantiles de la época. Intentaremos demostrar que si bien las diversas organizaciones cinematográficas iniciaron una corriente de cine militante en la que desarrollaron elaboraciones teóricas vinculadas a los movimientos guerrilleros, y pretendieron utilizar al cine como arma de combate; sin embargo sólo tuvieron productividad en el nivel ideológico, resultando frustradas sus aspiraciones de elaborar una especie de "cine-guerrilla". Discutiré el alcance de las ideas de un arte como praxis ante los acontecimientos históricos que condicionaron estas manifestaciones artísticas.

\section{RESUMO}

Destacaremos a maneira em que, desde a cinematografia de Argentina dos anos sessenta e setenta, produziu-se uma extensión das mobilizações políticas, operárias e estudantis da época. Tentaremos demonstrar que embora as diversas organizações cinematográficas iniciaram uma corrente de cinema militante na que desenvolveram elaborações teóricas vinculadas aos movimentos guerrilheiros, e pretenderam utilizar ao cinema como arma de combate; no entanto só tiveram a produtividade no nível ideológico, resultando frustradas suas aspirações de fazer um tipo do "cinema-guerrilla". Discutirei o alcance das idéias da arte como praxis ante os acontecimentos históricos que condicionaron estas manifestações artísticas.

\section{ABSTRACT}

We will mark the way that Argentine cinematography of the sixties 
and seventies, produced an extensión of the political mobilizations of workers and students of that time. We will try to demonstrate that although the different cinematographic organizations initiated a movement of militant cinema where they developed theories linked to guerrilla movements, and pretend to use cinema as a fight weapon; nevertheless they just had productivity in an ideological level, frustrating their aspirations of making a kind of 'guerrilla-cinema'. I will discuss the reach of the ideas of art as praxis among the historical events that conditioned these artistic manifestations.

A partir de la década del sesenta, en el cine argentino nació una nueva motivación que tuvo como fin reflejar los acontecimientos sociales y políticos del país, y analizar las causas que ocasionaron factores tales como el subdesarrollo, la dominación cultural y la explotación de los trabajadores. Es así como surgió un cine de intervención política que pretendió no solo testificar acerca de la inestabilidad reinante en la sociedad sino también denunciar e intervenir en la realidad histórica.

Este impulso en torno a lo político en las manifestaciones cinematográficas no se origina en la década del sesenta, sino que, al contrario, contiene antecedentes desde el comienzo mismo de esta actividad cultural en Argentina. Se pueden mencionar como ejemplos prototípicos de un cine que de alguna manera da cuenta de problemáticas de tipo social al film de Mario Soffici "Prisioneros de la tierra" (1939) y a "Las aguas bajan turbias" (1952), de Hugo del Carril ${ }^{1}$. Los diversos acontecimientos mundiales que se sucedieron previo y durante la década del sesenta (a saber, el movimiento de liberación en Argelia, el fracaso de las tropas norteamericanas en Vietnam, el triunfo de la Revolución
Cubana, y una tendencia ideológica anti-imperialista en el resto de Latinoamérica como consecuencia), impulsaron una movilización más áreas de la cultura con el objeto de utilizar al arte como una herramiendel neocolonialismo. También aportó su contribución la producción literaria de pensadores como Jean-Paul Sartre, Franz Fanon y Antonio Gramsci. Uno de los aspectos más destacados de la época es el fuerte sentimiento contra todo lo que proviniera de la cultura norteamericana, considerada fuente principal del imperialismo y enemiga a atacar. La influencia de Estados Unidos en la cultura y economía latinoamericana generó un movimiento contra la dependencia, que no fue ajeno al ámbito cinematográfico.

A pesar de este entusiasmo en pos de la desalienación del pueblo oprimido y de las expectativas ante la posibilidad de una verdadera revolución en Latinoamérica, no siempre ha sido positivo el saldo que las diversas organizaciones políticas obtuvieron en emprendimientos culturales asociados a sus proyectos. profunda y radical en las diversas ta más en la lucha por la liberación
1 Otros ejemplos se encuentran también en los films "El último malón" (1917), de Alcides Greca, "Juan sin ropa" (1919), de Georges Benoit, "Mujeres que trabajan" (1938), de Manuel Romero, "La guerra gaucha” (1942), de Lucas Demare, "Pelota de trapo" (1948), de Leopoldo Torres Ríos, y "Detrás de un largo muro" (1958), de Lucas Demare, entre muchas otras más. 
2 Entre sus películas filmadas hasta la década del setenta inclusive nos encontramos con los siguientes títulos, entre otros: "La primera fundación de Buenos Aires" (1959), "Buenos días, Buenos Aires" (1959), la mencionada "Tire dié" (1960), "Los inundados" (1962), "Che, Buenos Aires" (1962), "La Pampa gringa" (1963) y "Org" (1978). Birri retomaría la realización de films en 1983 con "Rafael Alberti, un retrato del poeta", "Rte.: Nicaragua (Carta al mundo)" (1984), "Mi hijo el Che" (1985), y "Un señor muy viejo con unas alas enormes" (1988), a la que sucederían varios años después sus cuatro últimas películas hasta la actualidad: "Che, muerte de una utopía?" (1997), aún no estrenada comercialmente, "Enredando sombras" (1998), "El siglo del viento" (1999) y "ZA 05. Lo viejo y lo nuevo" (2006).

3 Los títulos de estos manifiestos son: "Por un cine nacional, realista y crítico" (1958), "Manifiesto de Santa Fe" (1962), "Por un cine nacional, realista, crítico y popular" (1962), "Por un cine cósmico, delirante y lúmpen" (1979), "Por un nuevo, nuevo, nuevo cine latinoamericano" (1985) y "Por un cineteleasta de Tres Mundos en el 2000: Trabajadores de la luz" (1986).

4 PRT-ERP son las siglas del Partido Revolucionario de los Trabajadores, de ideología marxista, y de su organización armada, el Ejército Revolucionario del Pueblo.

\section{Dos alternativas contra la dominación cultural: denuncia social vs. militancia}

En el caso específico de Argentina, pueden remarcarse dos tipos de resultados en la realización de un cine de intervención política: la mera denuncia social y el compromiso radical y militante. Ambas tendencias pueden diferenciarse en la perspectiva a través de la cual se plantean las problemáticas sociales. La denuncia implica mostrar una situación alarmante para darla a conocer a los espectadores y producir, de esta manera, una especie de revelación o desenmascaramiento. La segunda vertiente apunta no sólo a "mostrar" sino también a analizar críticamente las causas que llevaron a aquella situación. La reflexión sobre las mismas llevaría a una denuncia frontal de los culpables y a posibles soluciones o métodos de lucha.

En el primer caso, los ejemplos más significativos han sido las realizaciones y elaboraciones teóricas de Fernando Birri, quien fundara en 1956 la Escuela Documental de Santa Fe en la Universidad Nacional del Litoral. Birri se destacó como un documentalista social del subdesarrollo, influido por la estética del neorrealismo italiano, de la cual bebió durante su formación cinematográfica en Italia. En su film "Tire dié" (1960), hecho en colaboración con sus alumnos y autoproclamado como la primera encuesta social filmada, se testifica sobre una de las realidades que azotan a la ciudad de Santa Fe, mostrando los modos de supervivencia de los niños y levantando testimonios al respecto.

Además de su labor educativa y su trayectoria como realizador ${ }^{2}$,
Birri dejó plasmados una serie de seis manifiestos ${ }^{3}$ en los que daría a conocer su pensamiento sobre la función que el cine político latinoamericano debería cumplir. Dando a entender que Latinoamérica ha realizado películas altamente colonizadas y creadoras de una falsa imagen del pueblo, en su "Manifiesto de Santa Fe", concluye que el cine debe "ponerse frente a la realidad con una cámara y documentarla, documentar el subdesarrollo. El cine que se haga cómplice de ese subdesarrollo, es subcine" (Citado en PARANAGUA, 2003, p. 457).

Como representantes centrales de la segunda vertiente cinematográfica, podemos mencionar dos organizaciones que se constituyeron en el tronco principal del cine político argentino de este período. En primer lugar, la agrupación Cine Liberación, fundada en 1969 por Fernando Solanas y Octavio Getino (vinculados al movimiento Montoneros y a la Juventud Peronista) y Cine de la Base (que tuvo como líder al realizador Raymundo Gleyzer) y se fundó en 1973 con bases políticas incrustadas en el PRT-ERP ${ }^{4}$. Junto con ellos ha habido un sinnúmero de realizadores que pusieron al servicio de la militancia política sus creaciones artísticas. Entre ellos podemos mencionar a Humberto Ríos, los hermanos Enrique y Nemesio Juárez, Pablo Szir, Gerardo Vallejo y Jorge Cedrón, entre otros. Las vinculaciones entre estos realizadores se fueron sucediendo a través de colaboraciones en áreas diversas de la producción de sus films y a través de un emprendimiento colectivo que resultó en la película "Argentina, mayo de 1969: los caminos de la liberación", compuesta por diez 
cortometrajes dirigidos por Nemesio Juárez, Humberto Ríos, Octavio Getino, Jorge Martín, Eliseo Subiela, Pablo Szir, Rodolfo Kuhn, Rubén Salguero y Mauricio Berú. La película fue realizada en 1969 y no tuvo la posibilidad de ser estrenada comercialmente.

Este grupo de cineastas se reunió especialmente para plasmar con este proyecto un testimonio sobre la experiencia del Cordobazo ${ }^{5}$ y conformar, a partir de ese momento, lo que denominaron Grupo Realizadores de Mayo. Junto a los nombres arriba mencionados hay que agregar a la nómina a Enrique Juárez, que realizó paralelamente un mediometraje sobre la misma temática titulado "Ya es tiempo de violencia" (1969), fuertemente influido por la estética de Cine Liberación. Este conjunto de directores nunca más volvió a juntarse como agrupación, por lo cual Realizadores de Mayo fue una experiencia efímera, que no pudo continuarse por la diversidad ideológica y la desigualdad en los niveles de compromiso militante de sus integrantes.

\section{Un cine para la liberación del Tercer Mundo}

Luego de la realización del documental "La hora de los hornos" (1966-68), Solanas y Getino impulsaron, a través de su organización, un cine destinado a luchar por la liberación del neocolonialismo y a renegar de la proscripción del peronismo. El segundo largometraje de Cine Liberación fue "El camino hacia la muerte del viejo Reales" (1971), dirigido por Gerardo Vallejo, un tucumano que colaboró en las realizaciones del grupo luego de haber estudiado en la Escuela Documental de Santa Fe. En este film, Vallejo relata los modos de supervivencia de los trabajadores azucareros, y para realizarla estuvo en contacto durante tres años con los protagonistas reales de la historia: Ramón Gerardo Reales y sus tres hijos.

El hecho de haber convivido con los sujetos a documentar responde al ímpetu de los cineastas de este período por cambiar su mentalidad aburguesada y experimentar en carne propia las vivencias de los personajes. Más allá de un afán antropológico, el objetivo era darle voz a esos sujetos, y no imponer, a través de una voz autoral, una interpretación colonizadora de esas vivencias. Personajes reales narrarían su propia historia, mientras el realizador plasma con su cámara esa memoria.

Otros films vinculados a Cine Liberación son "El familiar" (1972), de Octavio Getino (realizada para la $\mathrm{RAI}$ ), y la reconstrucción ficcional de los sucesos que llevaron al fusilamiento de sospechosos de la sublevación contra la Revolución Libertadora $^{6}$ por parte del General Juan José Valle en "Operación masacre" (1972), de Jorge Cedrón. Esta película se basó en la novela homónima de Rodolfo Walsh, y contó con la participación de uno de los sobrevivientes del acontecimiento, Julio Troxler (quien participaría tres veces en las producciones de Cine Liberación cumpliendo una función de actor testimonial ${ }^{7}$ ). En 1971, Solanas, Getino y Vallejo llegaron a Madrid para filmar largas entrevistas a Juan Domingo Perón, que se reunieron en dos películas tituladas "La revolución justicialista" (1971) y "Actualización
5 El Cordobazo fue el nombre que se le otorgó a una movilización espontánea de trabajadores y estudiantes de la ciudad de Córdoba luego de una serie de huelgas y del asesinato del obrero Máximo Mena el 29 de mayo de 1969.

6 Este es el nombre autoadjudicado por la dictadura que empezó el 16 de septiembre de 1955 al golpe que derrocó al presidente Juan Domingo Perón.

7 Los films a los que nos referimos son "La hora de los hornos", en donde relata su testimonio sobre este mismo acontecimiento, "Operación masacre", en la cual se interpreta a sí mismo, y "Los hijos de Fierro" (1975), de Fernando Solanas, en donde personifica al hijo mayor de Fierro/Perón (representante de la resistencia peronista). 
8 Nos referimos al personaje creado por José Hernández para sus obras tituladas "El gaucho Martín Fierro" (1872) y "La vuelta de Martín Fierro" (1879).

9 Esta tesis se encuentra desarrollada en el manifiesto "Hacia un Tercer Cine. Notas y experimentos para el desarrollo de un cine de liberación en el Tercer Mundo" (1969), de Fernando Solanas y Octavio Getino. política y doctrinaria para la toma del poder", del mismo año. Posteriormente, se abocarían a la ficción con "Los hijos de Fierro" (1975), en donde a partir de la figura literaria del título ${ }^{8}$, Solanas establece una analogía con el líder exiliado y su relación con los diferentes sectores de la sociedad argentina del momento.

Cine Liberación abogaba por un cambio integral en las estructuras cinematográficas de producción, distribución y recepción proclamando su famosa tesis sobre un "Tercer Cine". Esta consistió en una división de ese arte en tres categorías: el Primer Cine refiere a las películas hechas en Hollywood o que se inspiran en los patrones de ese cine industrial. El Segundo Cine remite a lo que se ha conocido como "cine de autor", en el cual en ocasiones se subvierten los esquemas estéticos y narrativos clásicos, pero sin salir del sistema productivo tradicional. El Tercer Cine, en cambio, es planteado como el único verdaderamente revolucionario, ya que se expresa como un cambio integral en todas las instancias de la realización de un film, desde la pre-producción, pasando por el rodaje, hasta llegar a la instancia receptora. Para llegar a tal fin había que destruir la influencia colonialista proveniente de Europa y Estados Unidos, despojando de toda raíz burguesa al realizador o conjunto de realizadores, para luego construir una nueva forma, afín al nuevo hombre revolucionario. El Tercer Cine nace en contraposición al cine-espectáculo, asociado siempre a la evasión, y por ende, a la alienación. A su vez, había que preocuparse por revolucionar el lenguaje cinematográfico. El cine militante sería una categoría interna de este Tercer Cine, el cual propone a los films como herramientas para la instrumentalización práctica.

Originalmente, Cine Liberación propuso la realización de un cine-guerrilla, en el cual la cámara se convertiría en un arma revolucionaria que dispara fotogramas. El objetivo sería hacer del receptor un espectador-actor, un sujeto que participara activamente en el film, y que no recibiera las imágenes pasivamente. Sería este el encargado de completar la película, siempre nueva en cada proyección, y discutirla. El cine propuesto por esta agrupación es declarado por ellos mismos como un "film-acto", cuyo fin central será hacer un llamado a la lucha armada. La frase de Franz Fanon citada en "La hora de los hornos" anunciando que "todo espectador es un cobarde o un traidor" resume esta posición asumida por el grupo.

\section{Llegando a las bases populares}

A diferencia de Cine Liberación, quienes ejercieron una postura bastante experimental en sus trabajos con cierta influencia de la estética de Bertolt Brecht y del cine soviético mudo (específicamente, el realizado por Serguei Eisenstein), los integrantes de Cine de la Base tuvieron una postura más simplista y menos formalista en su anhelo por llegar a las bases con un mensaje destinado específicamente a la contra-información. Esta prioridad era la política de Raymundo Gleyzer como cabeza central de Cine de la Base, en una declaración realizada en Pésaro en 1973: "Una vez que tomemos el poder, podemos permitirnos discusiones sobre proble- 
mas de estilo o construcción. Ahora no" (Citado en PEÑA; VALLINA, 2000, p. 124).

Así como el ERP se caracterizó por la "simplicidad de sus explicaciones y de sus pautas de acción..." (WALDMANN, 1982,p. 210), Cine de la Base tuvo una actitud similar, con el fin de poder alcanzar una mejor comunicabilidad con la masa de obreros destinatarios de sus films. Originalmente, fue un grupo concebido para facilitar la distribución cinematográfica. Se consolida como tal a partir de la filmación de uno de los pocos largometrajes de ficción de este cine de intervención política. Nos referimos a "Los traidores" (1973), dirigida por Gleyzer y en la cual se denuncia al sindicalismo argentino y su traición a la clase obrera. Este realizador tenía una trayectoria como periodista y director de fotografía, y como director de películas tales como el largometraje "México, la revolución congelada" (1970) y los cortometrajes "La tierra quema" (1964) y "Swift" (1970) ${ }^{10}$ (que sigue los lineamientos de los films del futuro Cine de la Base). A partir de "Los traidores" el equipo que conformó la agrupación desarrollaría una serie de películas ${ }^{11}$ que tendrán como objetivo denunciar, a través de fragmentos extraídos de los noticieros televisivos, la explotación de los trabajadores. Utilizarían recursos coercitivos para impulsar a los destinatarios del film (las clases bajas que no asistían al cine) a la lucha revolucionaria.

Cine de la Base terminó disolviéndose luego de la desaparición de Gleyzer en 1976, cerrándose su producción con el film "Las AAA son las tres armas" (1977), de Jorge Denti, en la que se lee en voz over la "Carta abierta de un escritor a la Junta Militar" que ese mismo año había redactado el escritor Rodolfo Walsh. Este film nunca llegaría a las salas comerciales argentinas, y sólo sería distribuido en el exterior.

\section{Conflictos y vinculaciones}

A pesar de varios momentos de colaboración entre ambas agrupaciones, entre los que se destacan la gestión de Cine de la Base para la difusión de "La hora de los hornos" y de "El camino hacia la muerte del viejo Reales", fueron distanciándose paulatinamente a causa de diferencias ideológicas. Cine Libera-ción fue centrándose cada vez más en el objetivo del retorno de Perón y a eso remiten prácticamente sus últimas producciones. En cambio, Cine de la Base prosiguió en reforzar la necesidad de sumar a los espectadores a las filas revolucionarias. Por otro lado, había un desacuerdo ideológico entre el nacionalismo peronista y el internacionalismo marxista que producía un choque entre ambas agrupaciones. Estas diferencias se empezaron a exacerbar a partir de 1973, cuando asume la presidencia de Argentina Héctor Cámpora y el ERP comienza a calificar el acontecimiento como un freno al "desarrollo revolucionario de las masas argentinas" (POZZI, 2001, p. 329). La asunción de Octavio Getino como director del Ente Nacional de Calificación Cinematográfica, entre agosto y noviembre de 1973 , si bien fue vista como positiva por la gestión del mismo para liberar varios films censurados ${ }^{12}$, fue considerada al mismo tiempo, por sectores ajenos al peronismo,
10 Este film, conocido también como "Comunicado Cinematográfico del ERP $\mathbf{N}^{\circ} \mathbf{5}$ y 7", fue realizado por Gleyzer en colaboración con Alvaro Medián y Nerio Barberis, quienes hicieron esta película y el "Comunicado Cinematográfico del ERP N²", sobre el asalto al Banco Nacional de Desarrollo, al servicio de la ideología del PRT. Estos films fueron realizados en el contexto del FATRAC (Frente Antiimperialista de Trabajadores de la Cultura), organismo creado por el ERP y orientado al área cultural.

11 La filmografía de Cine de la Base la componen los siguientes títulos: "Ni olvido ni perdón” (1972), "Los traidores" (1973), "Me matan si no trabajo y si trabajo me matan" (1974) y "Las AAA son las tres armas" (1977).

12 Entre los films argentinos liberados por lo que algunos llamaron "primavera camporista" se encuentran "Operación masacre" (1971), de Jorge Cedrón, "Informes y testimonios: la tortura política en Argentina. 1966-1972" (1972-73), de Diego Eijo, Eduardo Giorello, Ricardo Moretti, Alfredo Oroz, Silvia Verga y Carlos Vallina, y la primera parte de "La hora de los hornos", no sin previa modificación de su desenlace, en el cual se acortó la extensa duración del primer plano del Che Guevara muerto, y se agregaron imágenes de sucesos diversos de la actualidad argentina y latinoamericana. 
13 Una tercera organización protagonista de este acontecimiento fue la llamada Fuerzas Armadas Revolucionarias (FAR). como el comienzo de una institucionalización de Cine Liberación y el fin de toda colaboración mutua. El famoso comunicado del ERP a Cámpora hecho durante ese año anunciando que el ERP no dejará de combatir es una clara afirmación de las diferencias que empezaban a radicalizarse en estos años.

A modo de ilustración, basta citar la siguiente afirmación de Raymundo Gleyzer, hecha en 1971, para reafirmar los roces entre ambas formas de usar el cine políticamente: "... no me interesa tanto el elemento cultural que pueda irradiar una obra tercermundista sino su instrumentalización política ... [...] O te juegas entero por la Revolución Socialista o te dedicas a realizar un cine tercermundista $y$ andas escribiendo tu idea sobre lo que hay que hacer, sin hacerlo personalmente" (Citado en PEÑA; VALLINA, 2000, p. 71). Es sabido que una de las cosas que más ha abundado en Cine Liberación es la elaboración teórica a través de manifiestos y literatura de diverso tipo. El más importante de estos escritos es el ensayo "Hacia un Tercer Cine. Apuntes y experiencias para el desarrollo de un cine de liberación en el Tercer Mundo" (1969).

Otro de los motivos de separación entre ambas agrupaciones cinematográficas se debió al apoyo de Cine Liberación a la presidencia de Isabel Perón, heredera del gobierno al que los peronistas tanto habían aspirado desde el derrocamiento en 1955.

Uno de los enfrentamientos más fuertes entre Cine Liberación y Cine de la Base tuvo lugar con la polémica por la retención del estreno de "Los traidores" durante la gestión de Getino, hasta que el film fuera modificado en su desenlace, en el cual se proclama la justificación del asesinato de los sindicalistas burocratizados. La negativa del ERP llevó a que el film no pudiera ser estrenado.

Sin embargo, en "Ni olvido ni perdón" (1973), Cine de la Base unifica la lucha del ERP y Montoneros ante los enemigos comunes de la dictadura y el capitalismo. A través de entrevistas a guerrilleros de ambas organizaciones ${ }^{13}$ que se encuentran en la antesala del fusilamiento que acabaría con sus vidas en el aeropuerto de Rawson, este film patrocinado por el ERP llamaría a una unidad de las organizaciones armadas.

Esa misma solidaridad se repite en la mencionada "Swift", una especie de "anti-noticiero" que denuncia el estado en que trabajaban los obreros de la carne en el frigorífico del título, y donde se comunican los motivos del secuestro por parte del ERP del cónsul Stanley Silvester, gerente del lugar. La cámara encuadra, en un momento, una pintada realizada por la asociación Peronismo de Base, dando a conocer el intento por unir las diversas organizaciones guerrilleras por un fin común.

Tanto en la vertiente testimonial como en la militante, los cineastas que se dedicaron a filmar en estas décadas no eran autónomos sino que estaban conectados con todo un engranaje nacido de un movimiento de integración latinoamericana, que llevó a la vinculación constante entre los realizadores argentinos y sus pares de la región, brasileños y cubanos en su gran mayoría.

Raymundo Gleyzer filmó en Brasil su cortometraje "La tierra quema" junto con Jorge Giannoni, 
uno de los futuros integrantes de Cine de la Base. La misma interconexión con ese país tuvo el productor Edgardo Pallero, colaborador de Birri y de Cine Liberación. Por su parte, la relación de Fernando Solanas y Octavio Getino con Cuba se destaca a partir de las coincidencias teóricas con el director Julio García Espinosa, quien en su manifiesto "Por un cine imperfecto" (1969) establece, como los argentinos, la necesidad de ir contra el modelo de obra acabada y completa.

Esta integración ha tenido como punto geográfico común una serie de festivales de cine ${ }^{14} y$ congresos en los que se difundían los films de una manera libre, y donde los cineastas encontraban la oportunidad de intercambiar ideas. Por lo tanto, las agrupaciones cinematográficas argentinas mencionadas más arriba tienen en común la marcha en pos de una solidaridad continental sin la cual los esfuerzos hechos en el país no tendrían real fuerza revolucionaria.

Estas películas políticas tienen en común la elaboración de una nueva significación sobre la violencia, asociada siempre a una consecuencia por la violentización institucional perpetrada por el Gobierno y los poderosos. El no hacer uso de la violencia implicaba entonces resignación y rendición. Como se afirma en "Swift", la tendencia de esta época era no mendigar las conquistas del pueblo sino arrancarlas mediante la violencia. Tal como expresa Daniel James, “... bajo un régimen autoritario y represivo, la violencia aparecía cargada con un suplemento de legitimidad' (2003, p. 433). El paisaje común en el cine político argentino de los años sesen- ta y setenta contiene imágenes de multitudes huyendo de gases lacrimógenos, batallas urbanas entre policías y trabajadores, y testimonios orales y audiovisuales sobre fusilamientos, torturas y desapariciones.

Otro punto en común en estos grupos fue el anhelo por contrarrestar la desinformación y la mentira que consideraban rasgo principal de los medios de comunicación, utilizando los archivos de estos medios para el movimiento contrario. A su vez, sus integrantes no se planteaban a sí mismos como artistas individuales, sino como hombres en primer lugar. Las películas que hicieron no apuntaban a generar una propia estética autoral, sino que subordinaban el individuo al conjunto.

A diferencia del circuito por el cual circulaban las películas de corte industrial, estos films políticos abrieron un sistema de distribución alternativo, debido a la censura que no permitía su distribución libre. Así nacería un nuevo modo de proyectar films, que transformaría incluso el concepto tradicional de recepción cinematográfica. Las películas son exhibidas en sindicatos estudiantiles y obreros, en universidades, fábricas, escuelas y villas, e incluían debates posteriores a la proyección. El caso más significativo es la exhibición de "La hora de los hornos", proyectada públicamente por primera vez en la Muestra Internacional de Cine de Pésaro (Italia) en 1968, mientras que en Argentina tuvo una recepción sólo dentro de ámbitos clandestinos. La película volvió a exhibirse abiertamente el mismo año en la ciudad de Mérida (Venezuela), lugar que durante mucho tiempo difundió las producciones de cineastas políticos
13 Los festivales más trascendentales fueron los efectuados en la ciudad chilena de Viña del Mar en 1967 y 1969, y el que se llevó a cabo en Mérida (Venezuela) en 1968. 
latinoamericanos.

El film apela al espectador de una manera directa, invitándole a debatir durante y luego de la proyección. La película, que consta de tres partes ${ }^{15}$, podía presentarse de maneras variadas según la ocasión, y ser detenida en cualquier momento para dar lugar a la reflexión de los espectadores-autores. Estas proyecciones fueron una más de las maneras de agrupamiento de los trabajadores para conformar una conciencia obrera.

\section{Cine y Estado con y sin Perón}

Las películas argentinas hechas bajo la custodia del Estado Peronista se diferencian en gran manera del peronismo cinematográfico posterior al exilio del ex presidente. El cine realizado durante el período 1945 1955 era altamente proteccionista y nacionalista.

El estricto control por parte del Estado, que revisaba los guiones y de esa manera fomentaba la autocensura, fue regla general en este período. Entre las manifestaciones más notorias de esta condición se destaca la utilizaciones de recursos estilísticos tales como el flashback (el cual retrotraía la acción a un pasado lejano y superado) y los prólogos y epílogos (con leyendas incluidas) que marcaban directivas

15 A saber, "Neocolonialismo y violencia", "Peronismo y liberación" y "Violencia y liberación".

16 Nos referimos a los mencionados "La revolución justicialista" $y$ "Actualización política y doctrinaria para la toma del poder", ambas de 1971. normativas para guiar la interpretación del espectador.

El año 1947 fue crucial en esta tendencia al nombrarse a Raúl Alejandro Apold como Director de la Subsecretaría de Informaciones, con la tarea de revisar y elegir los argumentos de películas que fueran dignos de ser mostrados en la pantalla sin perjuicio de dar una mala imagen del país. Ese año también se dictó la Ley 12.999, con la cual se estableció una obligatoriedad en la exhibición de películas argentinas. Por otro lado, se destaca la influencia que han tenido los noticieros cinematográficos como "Sucesos argentinos", "Noticiario Panamericano", "Sucesos de las Américas", "Noticiario Lumiton" y "Semanario Argentino", entre otros, que daban a conocer a los espectadores de cine los diversos acontecimientos de la realidad nacional. El año 1943 inicia una nueva etapa al respecto a través del decreto 18.405 , que proclamaba la obligatoriedad de exhibición de noticieros antes de las proyecciones de films en las salas argentinas, y cuyo contenido debía servir de propaganda para el Gobierno.

Cuando se realizaron los documentales-reportaje hechos a Perón por parte del equipo de Cine Liberación ${ }^{16}$, el contexto histórico de la proscripción y la resistencia peronistas habían modificado las estructuras del cine anclado en la figura de Perón. En estas últimas películas (y en la entrevista incluida previamente en "La hora de los hornos"), podemos observar al ex presidente desde Madrid siendo entrevistado con su rostro en primer plano y ocupando el centro del encuadre, mientras efectúa un resumen de su carrera política, y propone la lucha organizada. Vemos a Perón ejerciendo el rol del conductor a la distancia, otorgando directivas para la organización del movimiento a través de una resistencia individual y organizada, ya sea por medio de actos pacíficos como también mediante la violencia, si fuera necesario. El llamado a la insurrección en pos del retorno de Perón tiene su extensión en este grupo de 
films, que serían herramientas extras de esa rebelión, junto con los sabotajes, las bombas y atentados contra los emblemas de la Revolución Libertadora.

Otra serie de películas, como las mencionadas "Argentina, mayo de 1969: los caminos de la liberación", y "Ya es tiempo de violencia", plantearon esperanzas similares sobre la lucha armada al espectador, pero esta vez fuera de los enunciados de esas dos organizaciones políticas cinematográficas. Ambos films, que documentan los acontecimientos que derivaron en el Cordobazo resaltan el poder de la clase obrera para organizarse espontáneamente por un fin común, fuera de las agrupaciones guerrilleras existentes en el momento ${ }^{17}$.

\section{Conclusión}

La inestabilidad institucional, que se convirtió en una constante a lo largo de la historia argentina, tuvo su repercusión también en el ámbito cultural, el cual nunca fue ajeno a los cambios perpetrados por los sucesivos golpes de Estado. El cine argentino de los años sesenta y setenta se constituye no sólo en un reflejo de la situación política y social, y sino también en un relato más de la Historia. No solamente se hablaría de la Revolución sino que también se trataría de llevarla a cabo.

Esa inestabilidad política hacía eco en las manifestaciones culturales del momento, a partir de un cine que aspiraba a un quiebre que no se redujese a lo meramente estético sino que también produjera un real cambio en la sociedad. Estos films no pretendían una simple modificación en los estatutos socioeconómicos sino más bien un giro total, una verdadera subversión del sistema. No aspiraban a establecer una mera reforma sino a generar una Revolución. Los actores de la misma no iban a ser los políticos ni los intelectuales y artistas, sino los obreros y campesinos, sujetos destinatarios de estas películas.

Todo esto que acabamos de mencionar ha sido manifestado durante un contexto de alta politización cultural, que iba en pos de un compromiso y una responsabilidad que debían estar impregnadas en todo artista e intelectual. Estos ya no podían ser solamente comentaristas de la realidad social sino autores y creadores de modificaciones. Cultura y realidad debían entrelazarse al servicio de un fin práctico. La regla general de aquellos que sostenían esta posición consistía en que era en vano hacer un arte que no tuviera resultados concretos en la realidad.

El cine político argentino del período 1968-1977 se destacó entonces como seguidor de una política colectivista que respondía según ellos a los intereses del pueblo. Los guerrilleros son descriptos como hijos del '69, como parte del pueblo que había salido espontáneamente a la calle a protestar. Así como Montoneros y el ERP se constituían a sí mismos como "brazos armados del pueblo", Cine Liberación y Cine de la Base se convirtieron en el "brazo cultural" de esas organizaciones.
13 Entre ellas se destacaron las siguientes: Fuerzas Armadas Revolucionarias (FAR), Fuerzas Armadas de Liberación (FAL), Fuerzas Armadas Peronistas (FAP), Ejército Revolucionario del Pueblo (ERP) y Montoneros. 


\section{Referências}

AMARAL, S; PLOTKIN, M. Perón. Del exilio al poder. Buenos Aires: Cántaro, 1993. 368p.

Cavarozzi, M. Autoritarismo y democracia. Buenos Aires: Eudeba, 2002. 192p.

ESPAÑA, C. (Dir.). Cine argentino. Modernidad y vanguardias I. Buenos Aires: Fondo Nacional de las Artes, 2005. 507p.

ESPAÑA, C. (Dir.). Cine argentino. Modernidady vanguardias II. Buenos Aires: Fondo Nacional de las Artes, 2005. 816p.

GETINO, O. (Comp.). Cine latinoamericano, economía y nuevas tecnologías. Buenos Aires: Legasa, 1988. 305p.

GETINO, O.; VELLEGGIA, S. El cine de las historias de la revolución. México DF: Secretaría de Educación Pública, Dirección General de Publicaciones y Medios, 2002. 192p.

GILLESPIE, R. Soldados de Perón. Los Montoneros. Buenos Aires: Grijalbo, 1997. 370p.

JAMES, D. (Dir.). Violencia, proscripción y autoritarismo (1955-1976). Buenos Aires: Editorial Sudamericana, 2003. 439p.

MESTMAN, M. La hora de los hornos. El peronismo y la imagen del Che. Secuencias, Madrid: Entimema, p. 52-61, N 10, 1999.

PARANAGUA, P.(Coord.). Cine documental en América Latina. Madrid: Cátedra, 2003. 544p.

PEÑA, F.; VALLINA, C. El cine quema. Raymundo Gleyzer. Buenos Aires: Ediciones de la Flor, 2000. 262p.

POZZI, P. Por las sendas argentinas. El PRT-ERP. La guerrilla marxista. Buenos Aires: Eudeba, 2001. 455p.

SABATO, J.; SCHVARZER, J. Funcionamiento de la economía y poder político en la Argentina: trabas para la democracia. La clase dominante en la Argentina moderna. Formación y características, Buenos Aires: CISEA/ Imago Mundi, p. 243-280, 1991.

SCHNEIDER, A. Los compañeros. Trabajadores, izquierda y peronismo (1955-1973). Buenos Aires: Imago Mundi, 2006. 780p.

SCHUMMAN, P. Historia del cine latinoamericano. Buenos Aires: Le- 
gasa, 1987.361p.

TAL, T. Del cine guerrilla a lo grotérico. La representación del latinoamericanismo en dos films de Fernando Solanas: La hora de los hornos y El viaje. Estudios interdisciplinario de América Latina en el Caribe, Vol. 9, $\mathrm{N}^{\circ}$ 1, enero-junio. 1998.

TAL, T. Pantallas y revolución. Una visión comparativa del Cine de Liberación y el Cinema Novo. Buenos Aires: Ediciones Lumiere, 2005. 320 p.

TERAN, O. Nuestros años sesentas. La formación de la nueva izquierda intelectual en la Argentina 1956-1966. Buenos Aires: Puntosur, 1991.

VIEITES, M. (Comp.). Fernando Birri. La primavera del patriarca. Buenos Aires: Museo del Cine Pablo C. Duckrós, 2004. 118p.

WALDMANN, P. Anomia social y violencia. Argentina, hoy. México: Siglo XXI, p. 206-248, 1982.

YOEL, G. (Comp.). Imagen, política y memoria. Buenos Aires: Libros del Rojas/UBA, 2002.301p.

\section{Filmografia considerada}

Las aguas bajan turbias (1952), de Hugo del Carril

Detrás de un largo muro (1958), de Lucas Demare

Tire dié (1960), de Fernando Birri

Los inundados (1962), de Fernando Birri

La tierra quema (1964), de Raymundo Gleyzer

La hora de los hornos (1966-68), de Fernando Solanas y Octavio Getino Argentina, mayo de 1969: los caminos de la liberación (1969), algunos de los cortos

Ya es tiempo de violencia (1969), de Enrique Juárez

El camino hacia la muerte del viejo Reales (1971), de Gerardo Vallejo

La revolución justicialista (1971), Cine Liberación

Actualización política y doctrinaria para la toma del poder (1971), Cine Liberación

Comunicado cinematográfico del ERP N’5 y N7: Swift (1970), de Raymundo Gleyzer

Ni olvido ni perdón (1973), Cine de la Base

Los traidores (1973), de Raymundo Gleyzer

Me matan si no trabajo y si trabajo me matan (1974), Cine de la Base Los hijos de Fierro (1975), de Fernando Solanas

Las AAA son las tres armas (1977), Cine de la Base 